\title{
Performance and Specificity of 6 Immunoassays for TSH Receptor Antibodies: A Multicenter Study
}

\author{
Tanja Diana $^{\mathrm{a}}$ Christian Wüster $^{\mathrm{b}}$ Paul D. Olivo ${ }^{c}$ Angelica Unterrainer $^{\mathrm{a}}$ \\ Jochem König $^{d}$ Michael Kanitz $^{a}$ Artur Bossowski ${ }^{\text {e }}$ Brigitte Decallonne $^{f}$ \\ George J. Kahaly ${ }^{a}$ \\ ${ }^{a}$ Molecular Thyroid Research Laboratory, Department of Medicine I, Johannes Gutenberg University (JGU) Medical \\ Center, Mainz, Germany; ${ }^{b}$ Endocrine Laboratory Prof. Wüster, Mainz, Germany; ${ }^{c}$ Department of Microbiology, \\ Washington University, St. Louis, MO, USA; ${ }^{d}$ Institute of Medical Biostatistics, Epidemiology and Informatics, \\ Johannes Gutenberg University (JGU) Medical Center, Mainz, Germany; ${ }^{\text {}}$ Department of Pediatrics, Endocrinology, \\ and Diabetology, Medical University of Byalistok, Bialystok, Poland; ${ }^{f}$ Division of Clinical and Experimental \\ Endocrinology, UZ Leuven, Leuven, Belgium
}

\section{Keywords}

Thyroid-binding inhibitory immunoglobulins . TSH receptor stimulating antibodies . TSH receptor blocking antibodies. Bioassays · Binding assays $\cdot$ Specificity

\footnotetext{
Abstract

Background: The measurement of TSH receptor (TSHR) antibodies is warranted for diagnosis of Graves' disease (GD). Objective: The performance, detection sensitivity, and specificity of 6 TSHR immunoassays were compared. Methods: Two bioassays and 4 binding assays (Kronus, Immulite, Kryptor, Dynex) were compared in a dilution study performed in patients with autoimmune thyroid disease. Both bioassays were compared to 2 binding assays using stimulatory (M22) and blocking (K1-70) monoclonal antibody (MAb) mixtures. Results: Thirty samples from stimulatory (TSAb)positive/blocking (TBAb)-negative patients with GD were diluted serially and measured in all assays. Samples were positive until dilution 1:2,187 in the TSAb bioassay, 1:81 in the
}

Immulite ( $p<0.002$ vs. bioassay) and Kronus ELISA ( $p=0.039$ ) assays, and 1:27 in the Kryptor and Dynex ELISA ( $p<0.001$ vs. bioassay). Ten samples from TBAb-positive/TSAb-negative patients with GD or Hashimoto's thyroiditis were positive in all binding assays. None of the binding assays differentiated between TSAb and TBAb. Mixtures of 100\% K1-70 (200 ng/ $\mathrm{mL}), 80 \% \mathrm{~K} 1-70+20 \% \mathrm{M} 22,60 \% \mathrm{~K} 1-70+40 \% \mathrm{M} 22,40 \%$ $\mathrm{K} 1-70+60 \% \mathrm{M} 22,20 \% \mathrm{~K} 1-70+80 \% \mathrm{M} 22$, and $100 \% \mathrm{M} 22$ $(20 \mathrm{ng} / \mathrm{mL})$ tested positive in both Immulite $(26.4,20.2,15.2$, $10.5,6.3,2.00 \mathrm{IU} / \mathrm{L})$ and Kronus assays (27.1, 23.3, 19.3, 12.0, $5.7,2.2 \mathrm{IU} / \mathrm{L}$ ). These MAb mixtures were tested in the TBAb bioassay and showed 82, 61, 24 (negative), -26 (negative), -77 (negative), and $-95 \%$ (negative) inhibition, respectively. Conclusions: The sample dilution study showed higher detection sensitivity for the TSAb bioassay, and the antibody mixture study demonstrated exclusive specificity of the bioassays over all automated and ELISA binding assays.

(C) 2017 European Thyroid Association Published by S. Karger AG, Basel

\section{KARGER}

E-Mail karger@karger.com www.karger.com/etj (c) 2017 European Thyroid Association

Published by S. Karger AG, Basel
Prof. George J. Kahaly

JGU Medical Center

Langenbeckstrasse 1

DE-55131 Mainz (Germany)

E-Mail kahaly@ukmainz.de 


\section{Introduction}

Antibodies (Ab) to the thyroid-stimulating hormone receptor (TSHR) may mimic [1-3] or block [4] the action of TSH or be functionally neutral [5]. TSHR stimulating $\mathrm{Ab}(\mathrm{TSAb})$ are responsible for many of the clinical manifestations of Graves' disease (GD) and are specific biomarkers [6-10] of this autoimmune thyroid disease (AITD). On the other hand, TSHR blocking Ab (TBAb) can also be found in AITD patients and may contribute to the hypothyroidism or atypical Hashimoto's thyroiditis (HT). Ever since the different functional activities of TSHR Ab have been recognized it has been suspected that certain patients might contain both TSAb and TBAb, and that this might explain the spectrum of clinical presentations. Indeed, recent evidence has proven that a patient can have both TSAb and TBAb by isolating monoclonal antibodies (MAb) with stimulatory and blocking activity from the lymphocytes of the same patient [11]. The measurement of TSAb and TBAb has potential clinical implications in the differential diagnosis of AITD, in predicting the outcome of GD after antithyroid drug treatment, in evaluating the risk of extrathyroidal manifestations of GD during pregnancy, and in predicting the likelihood of fetal/neonatal hyper- or hypothyroidism $[10,12]$. TSHR $\mathrm{Ab}$ can be measured with either a bioassay or a binding assay. However, bioassays have the advantage of indicating not only the presence of $\mathrm{Ab}$ but also their functional activity and potency.

Since no studies that compare the performance of TSHR Ab immunoassays are available, we aimed to measure the lowest possible $\mathrm{Ab}$ concentration in several immunoassays and to compare the performance of ELISA and automated assays. FDA-cleared and/or validated functional cell-based bioassays for the measurement of TSHR Ab, whose analytical performance has been published [13-15], were used for assay comparison. In the second part of this work, 2 human TSHR MAb were tested on an automated assay and an ELISA assay with regard to specific TSHR Ab functionality. Thus, in this study both patient sera containing polyclonal $\mathrm{Ab}$ and human MAb were applied.

\section{Material and Methods}

A total of 40 well-characterized patients with AITD were enrolled in this study. Samples were collected from 3 institutions (Johannes Gutenberg University [JGU] Medical Center, Mainz, Germany; Medical University of Bialystok, Poland; and UZ Leuven, Belgium) while measurements were performed in 2 laboratories
(JGU and Prof. Wüster, Mainz). HT was defined as a serum level of anti-thyroid peroxidase $\mathrm{Ab}$ above the reference range with or without increased serum concentration of anti-thyroglobulin $A b$, a hypoechoic appearance at thyroid ultrasound, and euthyroidism or hypothyroidism. GD was defined as positive TSHR Ab, suppressed baseline TSH, elevated free thyroid hormones (free triiodothyronine, fT3 and/or free thyroxine, fT4), and enhanced vascularization at thyroid ultrasound ("thyroid inferno"), with or without clinically manifestations of orbital disease. The study protocol was approved by the JGU Ethics Committee and was carried out in accordance with the ethical guidelines of the Helsinki Declaration. Informed consent was obtained from all participants investigated in the study.

Thyroid-Related Hormones and Antibodies

Serum concentrations of TSH, fT3, fT4, anti-thyroglobulin, and anti-thyroid peroxidase $\mathrm{Ab}$ were evaluated using electrochemiluminescence immunoassays (CLIA; Abbott, Wiesbaden, Germany) according to the manufacturer's instructions. For the diagnosis of GD, serum samples were measured for thyroid-binding inhibitory immunoglobulins (TBII) with the Cobas e411 analyzer, Elecsys (Roche Diagnostics, Mannheim, Germany). For the dilution analysis, TBII concentrations were measured with 4 different binding assays: Kronus (Star, ID, USA), Immulite $2000 \mathrm{XPi}$ (Siemens, Erlangen, Germany), Kryptor (ThermoFisher, Hennigsdorf, Germany), and DS2 (Dynex, TECOmedical, Bünde, Germany). All binding assays were performed according to the manufacturer's instructions.

\section{TSHR Stimulating and Blocking Antibody Bioassays}

Serum TSAb activity was measured with a chimeric TSHR bioassay (Quidel Corp., San Diego, CA, USA) according to manufacturer's instructions $[13,14,16]$. TSAb activity was reported as percentage of specimen-to-reference ratio (SRR\%) (cutoff SRR\% $<140)$. Serum TBAb activity was measured as described previously $[15,17]$. Blocking activity was defined as percent inhibition of luciferase expression relative to induction with bovine TSH alone (cutoff $<40 \%$ inhibition). All bioassay measurements were done in duplicate. Both bioassays have been validated [13-15], and the standardization of the TSAb bioassay was previously reported [16].

\section{Serial Dilution Analysis}

The TSAb bioassay was compared with the TBII assays using 30 serum samples from 30 untreated patients with GD. Serial 1:3 dilutions were performed on each serum sample $(200 \mu \mathrm{L})$ in duplicate into human TSAb-negative control serum $(400 \mu \mathrm{L}$ collected from a euthyroid, healthy subject devoid of thyroid, autoimmune, and oncological disease) up to a final dilution of 1:81. For samples still positive at 1:81, the dilution was extended to a final dilution of $1: 243,1: 729$ or $1: 2,187$.

Detection of Various Human TSHR MAb Mixtures with Stimulating (M22) and Blocking MAb (K1-70) Activities

$\mathrm{MAb}$ mixtures were diluted in control serum (collected from a healthy subject devoid of thyroid and autoimmune disease) with $20 \mathrm{ng} / \mathrm{mL}$ of TSAb M22 (Kronus) and $200 \mathrm{ng} / \mathrm{mL}$ of TBAb K1-70 (Kronus) at different ratios. Mixtures of $100 \% \mathrm{~K} 1-70(200 \mathrm{ng} / \mathrm{mL})$, $80 \% \mathrm{~K} 1-70(160 \mathrm{ng} / \mathrm{mL})+20 \% \mathrm{M} 22(4 \mathrm{ng} / \mathrm{mL}), 60 \% \mathrm{~K} 1-70(120$ $\mathrm{ng} / \mathrm{mL})+40 \% \mathrm{M} 22(8 \mathrm{ng} / \mathrm{mL}), 40 \% \mathrm{~K} 1-70(80 \mathrm{ng} / \mathrm{mL})+60 \% \mathrm{M} 22$ 
(12 ng/mL), 20\% K1-70 (40 ng/mL) + 80\% M22 (16 ng/mL), and $100 \% \mathrm{M} 22(20 \mathrm{ng} / \mathrm{mL})$ were prepared and measured in the TBAb bioassay and Immulite and Kronus assays following the manufacturers' instructions.

\section{Statistical Analysis}

Data of all figures are presented as mean \pm SEM. Data of thyroid-related hormones and $\mathrm{Ab}$ are shown as median and 25th and 75th percentiles. All experimental data were analyzed with GraphPad Prism Software, Inc. (version 5.04), San Diego, CA, USA. Positivity rates for each dilution were compared between TSAb and the different binding assays (TBII) by the McNemar test. Correlations between the TSAb bioassay and the 4 binding assays were assessed with the Spearman correlation coefficient and the corresponding test for zero correlation. All $p$ values were 2 -sided and considered significant when $p \leq 0.05$.

\section{Results}

The demographic and serological data of all 40 investigated patients with AITD are summarized in Table 1. Thirty well-characterized, untreated, hyperthyroid TSAb-positive/TBAb-negative patients with GD were included as well as 10 euthyroid (on levothyroxine) TBAbpositive/TSAb-negative patients with either GD or HT.

\section{Assay Performance}

The number of positive samples in all 30 hyperthyroid patients with GD, undiluted and at each dilution step (1:3 to $1: 2,187)$, measured in the TSAb bioassay and the Immulite, Kryptor, and 2 Kronus and Dynex ELISA assays are shown in Figure 1. The 30 undiluted serum samples from patients with GD were all positive in the TSAb bioassay, Kronus ELISA, and Immulite assay. However, only $25 / 30(83.3 \%)$ and $24 / 30(80 \%)$ were positive with the Kryptor and Dynex ELISA, respectively ( $p=0.063$ and $p=0.031$ vs. bioassay). The results of the 30 undiluted GD samples measured by the TSAb bioassay positively correlated with those measured by the Kronus ELISA ( $r=$ $0.538, p=0.002)$, Immulite $(r=0.779, p<0.001)$, Kryptor $(r=0.510, p=0.004)$, and Dynex $(r=0.613, p<0.001)$.

In the dilution analysis, samples were positive until dilution 1:2,187 in the TSAb bioassay, $1: 81$ in the Immulite $(p<0.002$ vs. bioassay) and Kronus ELISA $(p=0.039)$ assays, and 1:27 in the Kryptor and Dynex ELISA $(p<0.001$ vs. bioassay). The TSAb bioassay and TBII binding assay median and interquartile (25th and 75th percentile) values for 40 undiluted serum samples from patients with either GD or HT are shown in Table 2. Overall, the sample dilution study showed higher detection sensitivity for the TSAb bioassay.
Table 1. Demographic and serological data of the 40 investigated patients with autoimmune thyroid disease and positive thyroidbinding inhibitory immunoglobulins (TBII)

\begin{tabular}{lll}
\hline & $\begin{array}{l}\text { Untreated } \\
\text { hyperthyroid } \\
\text { patients with } \\
\text { Graves' disease }\end{array}$ & $\begin{array}{l}\text { Patients with either } \\
\text { Graves' disease or } \\
\text { Hashimoto's thyroiditis } \\
\text { on levothyroxine }\end{array}$ \\
\hline Patients, $N$ & 30 & 10 \\
Gender $(\mathrm{F} / \mathrm{M}), n$ & $23 / 7$ & $10 / 0$ \\
Age, years & $41.4(30.6-53.1)$ & $37(34.3-54.3)$ \\
TBII Cobas $(<1.75 \mathrm{IU} / \mathrm{L})$ & $6.4(3.6-14.8)$ & $34.3(10.8-40)$ \\
TSAb & positive & negative \\
TBAb & negative & positive \\
TSH $(0.4-4.9 \mathrm{mU} / \mathrm{L})$ & $0.01(0.01-0.01)$ & $0.09(0.01-2.2)$ \\
fT3 $(2-4.4 \mathrm{pmol} / \mathrm{L})$ & $6.5(4.7-8.2)$ & $3.9(3.2-5.7)$ \\
fT4 $(0.9-1.7 \mathrm{ng} / \mathrm{dL})$ & $1.9(1.6-2.4)$ & $1.2(1-2)$ \\
Tg Ab $(<4.1 \mathrm{IU} / \mathrm{mL})$ & $5.8(2.1-79.3)$ & $47.5(1.1-94.8)$ \\
TPO Ab $(<6 \mathrm{IU} / \mathrm{mL})$ & $215.5(3-820)$ & $232(20.5-373)$ \\
\hline
\end{tabular}

$\mathrm{TSH}$, thyroid-stimulating hormone; TSAb, TSH receptor stimulating $\mathrm{Ab}$; TBAb, TSH receptor blocking $\mathrm{Ab}$; fT3, free triiodothyronine; fT4, free thyroxine; $\mathrm{Tg} \mathrm{Ab}$, anti-thyroglobulin $\mathrm{Ab}$; TPO Ab, anti-thyroid peroxidase $\mathrm{Ab}$.

\section{Functional TSHR Antibody Specificity}

Ten TBAb-Positive AITD Patients Tested in the Bioand Binding Assays

All $30 \mathrm{TSAb}$-positive GD patients were negative for TSHR blocking $\mathrm{Ab}$ as tested in the TBAb bioassay. On the other hand, 10 patients with AITD (GD: $n=6$, HT: $n=4$ ) were exclusively positive for TBAb in the TBAb bioassay and were negative for TSAb in the TSAb bioassay. All 10 TBAb-positive/TSAb-negative serum samples tested positive in the 4 binding assays: Immulite, Kronus, Kryptor, and Dynex (Table 3).

\section{Monoclonal Antibodies}

Mixtures of $100 \% \mathrm{~K} 1-70$ (200 ng/mL), 80\% K1-70 $(160 \mathrm{ng} / \mathrm{mL})+20 \% \mathrm{M} 22(4 \mathrm{ng} / \mathrm{mL}), 60 \% \mathrm{~K} 1-70(120 \mathrm{ng} /$ $\mathrm{mL})+40 \% \mathrm{M} 22(8 \mathrm{ng} / \mathrm{mL}), 40 \% \mathrm{~K} 1-70(80 \mathrm{ng} / \mathrm{mL})+60 \%$ M22 (12 ng/mL), 20\% K1-70 (40 ng/mL) + 80\% M22 (16 $\mathrm{ng} / \mathrm{mL}$ ), and $100 \% \mathrm{M} 22(20 \mathrm{ng} / \mathrm{mL}$ ) were $39,80,165$ (positive), 262 (positive), 361 (positive), and 415 (positive) SRR\%, respectively, for the TSAb bioassay, as presented in Figure 2a, while they were 82, 61, 24 (negative), -26 (negative), -77 (negative), and -95\% (negative) inhibition, respectively, for the TBAb bioassay, as shown in Figure $2 \mathrm{~b}$. The TBAb bioassay showed $100 \%$ specificity when testing M22 stimulating $\mathrm{Ab}$ and $\mathrm{K} 1-70$ blocking $\mathrm{Ab}$ concurrently. Mixtures of 100\% K1-70 (200 ng/mL), 80\% 


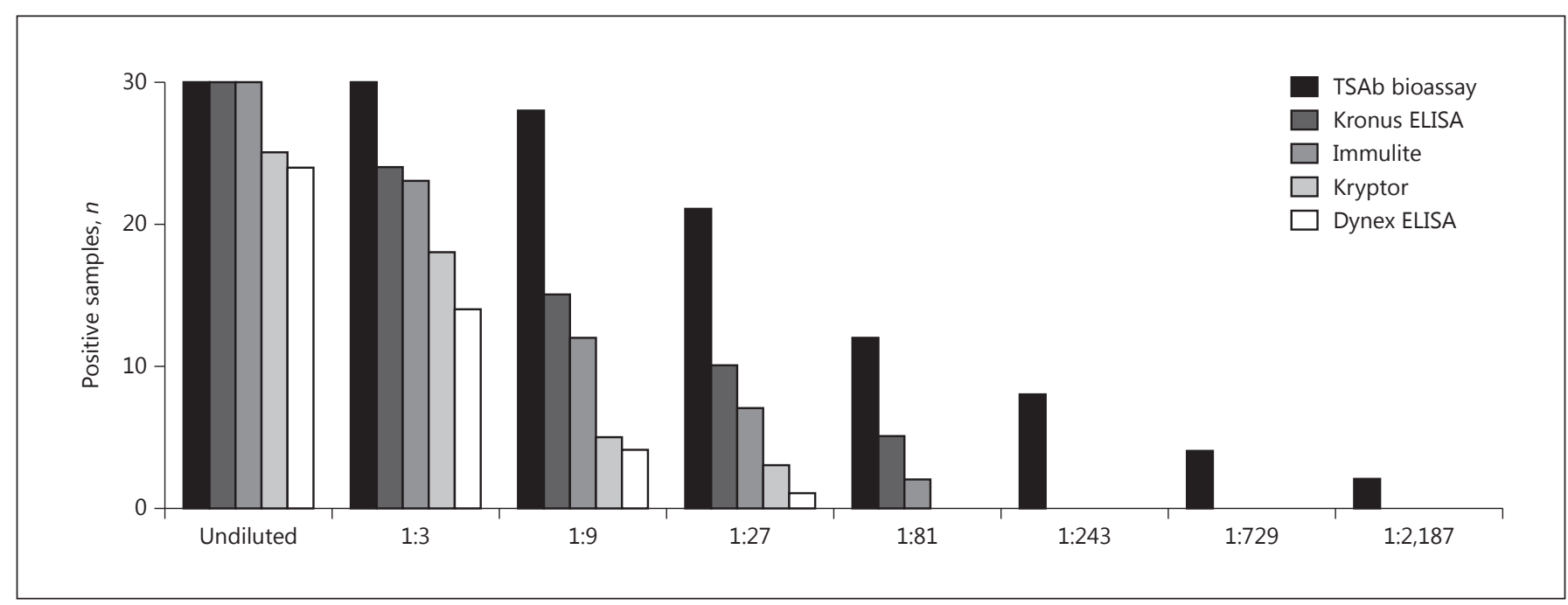

Fig. 1. Comparison of results for TSHR Ab binding immunoassays and a TSAb bioassay on undiluted and diluted (1:3 to 1:2,187) samples from 30 hyperthyroid patients with untreated GD. The bars indicate the number of positive samples for the TSAb bioassay, Kronus ELISA, Immulite, Kryptor, and Dynex ELISA, respectively. On undiluted samples, differences were noted between the bioassay and the Kryptor $(p=0.063)$ and Dynex $(p=0.031)$. Already on the 1:3 dilution, marked differences were observed between the TSAb bioassay and the Kronus ELISA $(p=0.031)$, Immulite $(p=$ $0.016)$, Kryptor $(p<0.001)$, and Dynex ELISA $(p<0.001)$. On both 1:9 and 1:27 dilutions, major differences were noted between the TSAb bioassay and all 4 binding assays (all $p<0.001$ ). On the 1:81 dilution, differences were still observed between the TSAb bioassay and the Kronus ELISA, $(p=0.039)$ and Immulite $(p=0.002)$.
Table 2. TBII binding assay and TSAb/ TBAb bioassay values in 40 undiluted serum samples from patients with autoimmune thyroid disease

\begin{tabular}{lcc}
\hline & $\begin{array}{l}\text { Untreated hyperthyroid } \\
\text { patients with Graves' } \\
\text { disease }\end{array}$ & $\begin{array}{l}\text { Patients with Graves' } \\
\text { disease or Hashimoto's } \\
\text { thyroiditis on } \\
\text { levothyroxine }\end{array}$ \\
\hline Patients, $N$ & 30 & 10 \\
Kronus Elisa $(<1 \mathrm{IU} / \mathrm{L})$ & $10(4.9 ; 14.8)$ & $30(25.8 ; 39.3)$ \\
Dynex Elisa $(<2 \mathrm{U} / \mathrm{L})$ & $6.1(3 ; 14.3)$ & $45(34 ; 51.5)$ \\
Immulite $(<0.55 \mathrm{IU} / \mathrm{L})$ & $3.5(1.5 ; 8.9)$ & $36.3(3.1 ; 40)$ \\
Kryptor $(<1.8 \mathrm{IU} / \mathrm{L})$ & $4.9(2.6 ; 9.5)$ & $18.8(16 ; 53.4)$ \\
TSAb bioassay $(<140$ SRR\%) & $367(242 ; 472)$ & $70(53 ; 92)$ \\
TBAb bioassay $(<40 \%$ inhibition $)$ & $-121(-156 ;-75)$ & $82(68 ; 99)$ \\
\hline
\end{tabular}

TBII, thyroid-binding inhibitory immunoglobulins; TSAb, thyroid-stimulating hormone receptor stimulating Ab; TBAb, thyroid-stimulating hormone receptor blocking $\mathrm{Ab}$; SRR\%, specimen-to-reference ratio.
$\mathrm{K} 1-70(160 \mathrm{ng} / \mathrm{mL})+20 \% \mathrm{M} 22(4 \mathrm{ng} / \mathrm{mL}), 60 \% \mathrm{~K} 1-70$ $(120 \mathrm{ng} / \mathrm{mL})+40 \% \mathrm{M} 22(8 \mathrm{ng} / \mathrm{mL}), 40 \% \mathrm{~K} 1-70(80 \mathrm{ng} /$ $\mathrm{mL})+60 \% \mathrm{M} 22(12 \mathrm{ng} / \mathrm{mL}), 20 \% \mathrm{~K} 1-70(40 \mathrm{ng} / \mathrm{mL})+$ $80 \% \mathrm{M} 22(16 \mathrm{ng} / \mathrm{mL})$, and $100 \% \mathrm{M} 22(20 \mathrm{ng} / \mathrm{mL})$ all tested positive in both the Immulite $(26.4,20.2,15.2,10.5$, 6.3, 2.00 IU/L) (Fig. 2c) and the Kronus assays (27.1, 23.3, 19.3, 12.0, 5.7, $2.2 \mathrm{IU} / \mathrm{L}$ ) (Fig. 2d). Overall, the antibody mixture study demonstrated higher specificity of the bioassays over the binding assays.

\section{Discussion}

This original study compared for the first time the assay performance and dilution analysis of 6 immunoassays using well-characterized serum samples from clearly defined patients with AITD. This comparative immunoassay study encompassed both newly introduced automated binding assays, widely distributed ELISA assays, and FDA-cleared and/or validated cell-based bioassays. The 
Fig. 2. Comparison of the TSAb/TBAb bioassays and 2 immunoassay results of mixtures of M22 and K1-70 MAb. a TSAb bioassay. The MAb mixtures are shown on the $x$ axis and the percentage of specimen-toreference ratio (SRR\%) on the $y$ axis. The dashed line indicates the cutoff at 140 SRR\%. Mean \pm SEM values are shown. b TBAb bioassay. The MAb mixtures are shown on the $x$ axis and the percent inhibition on the $y$ axis. Positive percent inhibition reflects blocking activity and negative percent inhibition reflects stimulating activity. The dashed line indicates the assay cutoff at $40 \%$ inhibition. Mean \pm SEM values are shown. c Immulite assay. The MAb mixtures are shown on the $x$ axis and international units per liter (IU/L) on the $y$ axis. The dashed line indicates the assay cutoff at $0.55 \mathrm{IU} / \mathrm{L}$. Mean \pm SEM values are shown. d Kronus assay. The MAb mixtures are shown on the $x$ axis and international units per liter (IU/L) on the $y$ axis. The dashed line indicates the assay cutoff at $1 \mathrm{IU} / \mathrm{L}$. Mean \pm SEM values are shown.

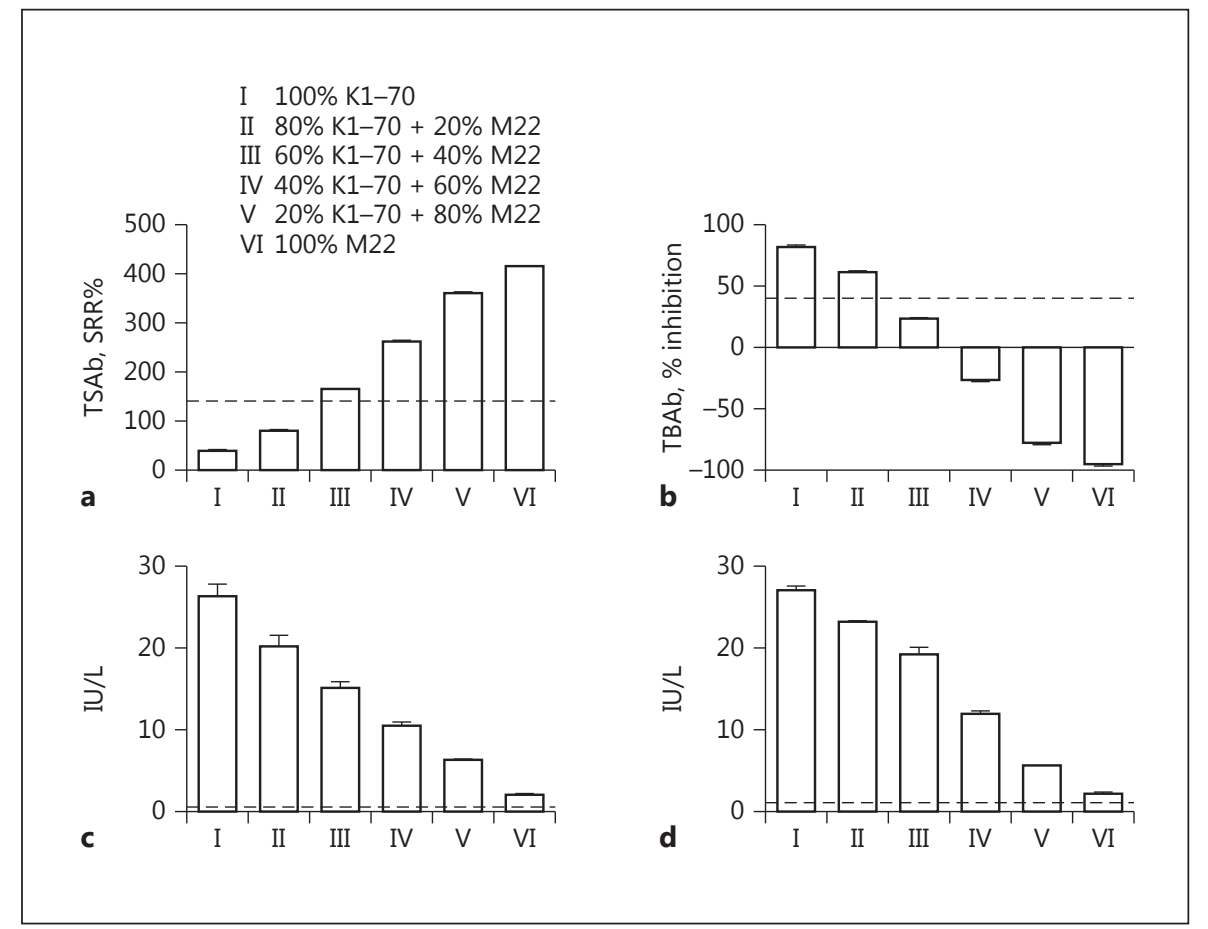

Table 3. Binding assay and bioassay results for $10 \mathrm{TBAb}$-positive/TSAb-negative samples from patients with autoimmune thyroid disease (either Hashimoto's thyroiditis or Graves' disease)

\begin{tabular}{|c|c|c|c|c|c|c|}
\hline $\begin{array}{l}\text { Patients with } \\
\text { AITD }\end{array}$ & $\begin{array}{l}\text { TBAb bioassay } \\
\text { (<40\% inhibition) }\end{array}$ & $\begin{array}{l}\text { Immulite } \\
(<0.55 \mathrm{IU} / \mathrm{L})\end{array}$ & $\begin{array}{l}\text { Kronus Elisa } \\
(<1 \mathrm{IU} / \mathrm{L})\end{array}$ & $\begin{array}{l}\text { Kryptor } \\
(<1.8 \text { IU/L) }\end{array}$ & $\begin{array}{l}\text { Dynex Elisa } \\
(<2 \mathrm{U} / \mathrm{L})\end{array}$ & $\begin{array}{l}\text { TSAb bioassay } \\
(<140 \text { SRR\%) }\end{array}$ \\
\hline 1 & 100 & $>40$ & $>40$ & 18.5 & 35.9 & 56 \\
\hline 3 & 84 & $>40$ & 38 & 18.5 & 41.1 & 45 \\
\hline 4 & 98 & 34 & 39 & 16.5 & 39.1 & 36 \\
\hline 5 & 83 & 0.784 & 32 & 1.9 & 2.1 & 78 \\
\hline 8 & 78 & 33.2 & 26 & 55.5 & 53.0 & 91 \\
\hline 9 & 81 & 2.03 & 28 & 52.7 & 48.9 & 89 \\
\hline 10 & 59 & 3.47 & 19 & 56.8 & 52.0 & 61 \\
\hline
\end{tabular}

AITD, autoimmune thyroid disease; TSAb, thyroid-stimulating hormone receptor stimulating Ab; TBAb, thyroid-stimulating hormone receptor blocking Ab; SRR\%, specimen-to-reference ratio.

direct comparison demonstrated significant differences in the performance of the 6 assays. The most striking difference was the higher sensitivity of the cell-based TSAb bioassay, which remained positive both at the highest dilution of sera and at the lowest antibody concentration. Surprisingly, the performance was better in an ELISA assay, using the MAb M22 as a ligand to the TSHR, com- pared to the latest generation of automated TSHR Ab binding assays.

All patients with AITD were carefully selected according to the diagnoses of GD and HT defined in the recently published guidelines of the American Thyroid Association (ATA) on hyperthyroidism management [18]. The serum samples from untreated patients with GD 
were tested and reproduced at least 3 times in the TSAb bioassay. Marked and statistically significant differences were then noted in the undiluted patient serum samples between the TSAb bioassay and 2 out of 4 binding assays. A significant lower accuracy and sensitivity was observed, especially between the bioassay and the Kryptor and Dynex assays. Furthermore, the dilution analysis demonstrated marked differences between the bioassay and all 4 binding assays at high dilutions. In comparison, a dilution analysis of 20 untreated patients with GD selected from a prospective trial with antithyroid drug treatment demonstrated large and significant differences between the bioassay and the automated Cobas binding assay, with 250- to 800 -fold differences of magnitude pertaining to the limit of detection, limit of quantitation, and half-maximal effective concentration, $\mathrm{EC}_{50}$ [14]. To the best of our knowledge, there are no other studies on dilution analysis that allow a direct comparison of results from multiple commonly used anti-TSHR assays.

The considerably higher performance of the bioassays could be clinically relevant in a number of circumstances, such as in patients with low serum TSHR Ab levels which may be observed in mild and/or subclinical thyroid dysfunction, in recent onset of GD, and in the euthyroid variant of orbitopathy. Furthermore, it has been reported that both children [19] and adults with euthyroid orbitopathy $[10,20,21]$ can test positive for TSAb and negative for TBII. Greater assay sensitivity might also lead to improved follow-up during the medical management of patients with Graves' hyperthyroidism and timing of treatment cessation. Accurate measurement of these $\mathrm{Ab}$ at the end of the usual 1-year treatment period would be clinically useful in deciding whether or not to terminate treatment.

The second part of this work showed the exclusive capability of the bioassays to specifically identify TSHR Ab functionality. Indeed, only bioassays were able to exclusively differentiate between TSHR stimulating and blocking $\mathrm{Ab}$ activity. For example, 10 samples from well-defined patients with AITD were positive for TSHR blocking $\mathrm{Ab}$ and negative for TSHR stimulating $\mathrm{Ab}$ in the cell-based bioassays. However, all patients tested positive in the automated (Immulite and Kryptor) and ELISA (Kronus and Dynex) binding assays. Distinguishing between TSAb and TBAb is relevant for accurate diagnostic and therapeutic management of AITD, especially during the critical period of pregnancy and postpartum, during AITD progression, and during the medical management of patients with Graves' hyperthyroidism. Both a shift from stimulatory to blocking activity during pregnancy
[22] and spontaneous changes of TSHR Ab functionality [23] have been described. Within a large prospective trial in patients with GD performed at our institution, medical antithyroid treatment led to either a shift of $\mathrm{Ab}$ functionality and/or the appearance of both stimulating and blocking TSHR Ab in approximately $10 \%$ of the treated patients [24]. Also, the presence of blocking TSHR Ab had a significant impact on the probability of remission. Finally, blocking TSHR Ab caused hypothyroidism in patients with AITD, foremost in HT $[25,26]$.

In summary, the results obtained in the present study support both superior performance and exclusive functional Ab specificity of the cell-based bioassays compared to novel automated and widely distributed ELISA binding assays. These results have implications for the clinical management of patients with AITD.

\section{Acknowledgments}

We thank E. Kolbe and J. Zimmermann (JGU Thyroid Laboratory) for blood specimen and data collection as well as S. Lütkemeier and S. Thumerer (Laboratory Prof. Wüster) for excellent laboratory work.

\section{Statement of Ethics}

This research complies with the guidelines for human studies.

\section{Disclosure Statement}

T.D., C.W., A.U., J.K., M.K., A.B., and B.D. have nothing to disclose. P.D.O. and G.J.K. consult for Quidel.

References

1 Smith TJ, Hegedus L: Graves' disease. N Engl J Med 2016;375:1552-1565.

-2 Bartalena L: Diagnosis and management of Graves disease: a global overview. Nat Rev Endocrinol 2013;9:724-734.

- 3 Bartalena L, Burch HB, Burman KD, Kahaly GJ: A 2013 European survey of clinical practice patterns in the management of Graves' disease. Clin Endocrinol (Oxf) 2016;84:115120.

4 Smith BR, Furmaniak J, Sanders J: TSH receptor blocking antibodies. Thyroid 2008; 18:1239.

$\checkmark 5$ Morshed SA, Ando T, Latif R, Davies TF: Neutral antibodies to the TSH receptor are present in Graves' disease and regulate selective signaling cascades. Endocrinology 2010; 151:5537-5549. 
-6 Ponto KA, Diana T, Binder H, Matheis N, Pitz S, Pfeiffer N, Kahaly GJ: Thyroid-stimulating immunoglobulins indicate the onset of dysthyroid optic neuropathy. J Endocrinol Invest 2015;38:769-777.

-7 Kampmann E, Diana T, Kanitz M, Hoppe D, Kahaly GJ: Thyroid stimulating but not blocking autoantibodies are highly prevalent in severe and active thyroid-associated orbitopathy: a prospective study. Int J Endocrinol 2015;2015:678194.

-8 Ponto KA, Schuppan D, Zwiener I, Binder H, Mirshahi A, Diana T, Pitz S, Pfeiffer N, Kahaly GJ: Thyroid-associated orbitopathy is linked to gastrointestinal autoimmunity. Clin Exp Immunol 2014;178:57-64.

-9 Jacobson DL, Gange SJ, Rose NR, Graham NM: Epidemiology and estimated population burden of selected autoimmune diseases in the united states. Clin Immunol Immunopathol 1997;84:223-243.

$>10$ Kahaly GJ, Diana T, Glang J, Kanitz M, Pitz S, Konig J: Thyroid stimulating antibodies are highly prevalent in Hashimoto's thyroiditis and associated orbitopathy. J Clin Endocrinol Metab 2016;101:1998-2004.

-11 Evans M, Sanders J, Tagami T, Sanders P, Young S, Roberts E, Wilmot J, Hu X, Kabelis K, Clark J, Holl S, Richards T, Collyer A, Furmaniak J, Smith BR: Monoclonal autoantibodies to the TSH receptor, one with stimulating activity and one with blocking activity, obtained from the same blood sample. Clin Endocrinol (Oxf) 2010;73:404-412.

$>12$ Kiefer FW, Klebermass-Schrehof K, Steiner M, Worda C, Kasprian G, Diana T, Kahaly GJ, Gessl A: Fetal/neonatal thyrotoxicosis in a newborn from a hypothyroid woman with Hashimoto's thyroiditis. J Clin Endocrinol Metab 2017;102:6-9.
13 Lytton SD, Li Y, Olivo PD, Kohn LD, Kahaly GJ: Novel chimeric thyroid-stimulating hormone-receptor bioassay for thyroid-stimulating immunoglobulins. Clin Exp Immunol 2010;162:438-446.

14 Leschik JJ, Diana T, Olivo PD, Konig J, Krahn U, Li Y, Kanitz M, Kahaly GJ: Analytical performance and clinical utility of a bioassay for thyroid-stimulating immunoglobulins. Am J Clin Pathol 2013;139:192-200.

15 Diana T, Li Y, Olivo PD, Lackner KJ, Kim H, Kanitz M, Kahaly GJ: Analytical performance and validation of a bioassay for thyroid blocking antibodies. Thyroid 2016;26:734740 .

16 Diana T, Kanitz M, Lehmann M, Li Y, Olivo PD, Kahaly GJ: Standardization of a bioassay for thyrotropin receptor stimulating autoantibodies. Thyroid 2015;25:169-175.

-17 Li Y, Kim J, Diana T, Klasen R, Olivo PD, Kahaly GJ: A novel bioassay for anti-thyrotrophin receptor autoantibodies detects both thyroid-blocking and stimulating activity. Clin Exp Immunol 2013;173:390-397.

18 Ross DS, Burch HB, Cooper DS, Greenlee MC, Laurberg P, Maia AL, Rivkees SA, Samuels M, Sosa JA, Stan MN, Walter MA: 2016 American Thyroid Association guidelines for diagnosis and management of hyperthyroidism and other causes of thyrotoxicosis. Thyroid 2016;26:1343-1421.
9 Diana T, Brown RS, Bossowski A, Segni M, Niedziela M, Konig J, Bossowska A, Ziora K, Hale A, Smith J, Pitz S, Kanitz M, Kahaly GJ: Clinical relevance of thyroid-stimulating autoantibodies in pediatric Graves' disease - a multicenter study. J Clin Endocrinol Metab 2014;99:1648-1655.

20 Ponto KA, Binder H, Diana T, Matheis N, Otto AF, Pitz S, Pfeiffer N, Kahaly GJ: Prevalence, phenotype, and psychosocial well-being in euthyroid/hypothyroid thyroid-associated orbitopathy. Thyroid 2015;25:942-948.

21 Lytton SD, Ponto KA, Kanitz M, Matheis N, Kohn LD, Kahaly GJ: A novel thyroid stimulating immunoglobulin bioassay is a functional indicator of activity and severity of Graves' orbitopathy. J Clin Endocrinol Metab 2010;95:2123-2131.

22 Kung AW, Jones BM: A change from stimulatory to blocking antibody activity in Graves' disease during pregnancy. J Clin Endocrinol Metab 1998;83:514-518.

23 McLachlan SM, Rapoport B: Thyrotropinblocking autoantibodies and thyroid-stimulating autoantibodies: potential mechanisms involved in the pendulum swinging from hypothyroidism to hyperthyroidism or vice versa. Thyroid 2013;23:14-24.

24 Kahaly GJ, Kanitz M, Kolbe E, Matheis N, Diana T: Thyroid stimulating autoantibodies are clinically useful and predictive in Graves' disease - a prospective trial. Eur Thyroid J 2014;3(suppl 1):24

25 Spaulding SW: Patients with TSH-receptor blocking antibodies give a "positive" result for stimulating activity in several commercial assays. Clin Thyroidol 2016;28:206-207.

26 Diana T, Wuster C, Kanitz M, Kahaly GJ Highly variable sensitivity of five binding and two bio-assays for TSH-receptor antibodies. J Endocrinol Invest 2016;39:1159-1165. 